\title{
REESTRUTURAÇÃO URBANA E VALORIZAÇÃO IMOBILIÁRIA EM LONDRINA - PR
}

\section{Urban Restructuring and Real Estate Valorization in Londrina - PR}

Msc Wagner Vinicius Amorim

Doutorando em Geografia - Universidade Estadual Paulista/PP Caixa Postal 266, Rua Roberto Simonsen, 305, CEP: 19060-900 - Presidente Prudente (SP), Brasil Tél/Fax: (+55 18) 32295316 / 32234519 - wagner_g3@yahoo.com.br

\section{$a a_{a} a$}

\begin{abstract}
Resumo
O artigo analisa a produção do espaço urbano e suas articulações com o mercado imobiliário, a partir da realidade concreta investigada na cidade de Londrina - PR. Os objetivos consistem em analisar a expansão da malha urbana e a evolução dos preços fundiários, no fito de apreender o processo de valorização seletiva do espaço engendrado pelos mecanismos próprios do circuito imobiliário. Assim, a conjuntura da última década foi base do processo investigativo. No entanto, a compreensão da expansão físico-territorial diz respeito às accões historicamente realizadas por agentes responsáveis pela produção do espaço urbano sob o modo capitalista de produção: os agentes privados, o Estado, e a sociedade civil. Desse modo, realizamos uma reflexão sobre a atuação dos incorporadores de loteamentos nas últimas quatro décadas, bem como da atuação do Estado na promoção da habitação e estruturação da cidade. Constituído esse quadro analítico, a compreensão volta-se ao estudo da evolução do preço da terra urbana a partir do levantamento e mapeamento das variáveis disponíveis nos classificados de terrenos do principal jornal local. Por fim, analisamos a estruturação do espaço urbano pela dinâmica da atividade imobiliária na Zona Leste da cidade.
\end{abstract}

Palavras-chave: produção do espaço urbano, reestruturação urbana, mercado imobiliário, renda da terra.

\begin{abstract}
The paper analyzes the production of urban space and its articulation with the real estate market, based on the reality investigated in Londrina - PR. The aim is to examine the expansion and evolution of the urban land prices in order to grasp the process of selective enhancement of space engendered by the mechanisms of the circuit real state. Thus, the conjuncture of the last decade was substratum for the investigative process. However, the physical-territorial expansion respect to actions undertaken by agents historically responsible for the production of urban space under the capitalist mode of production: private agents, the state and civil society. We reflect on the action of lots' developers in the last four decades, and the State, the promotion of housing and structuring of the city. Comprising this analytical framework, the study turns to the evolution of urban land prices from the survey and mapping thevariables in land classified in the largest local circulation newspaper site. Finally, we try to analyze the structure of urban space by the dynamics of real estate activity, investigating the more specific case of the East Side.
\end{abstract}

Key words: production of urban space, urban restructuring, real estate market, land rent.

\section{Resumen}

Este artículo analiza la producción del espacio urbano y sus articulaciones con el mercado inmobiliario, a partir de la realidad concreta investigada en la ciudad de Londrina - Estado de Paraná. Se propone como objetivo analizar la expansión de la malla urbana y la evolución de los precios de la tierra urbana, con el ánimo de entender el proceso de valoración selectiva del espacio generado por los mecanismos propios del circuito inmobiliario. Así, la coyuntura de la última década fue la base del proceso investigativo. Para entender la expansión física-territorial es necesario destacar las acciones históricamente realizadas por los agentes responsables de la producción del espacio urbano bajo el modo capitalista de producción: agentes privados, Estado y Sociedad Civil. Se elabora una reflexión acerca de la actuación de los incorporadores de loteamientos en las últimas cuatro décadas, así como la actuación del Estado en la promoción de la vivienda y estructuración de la ciudad. Después de realizado este cuadro analítico, la atención se centra en el estudio de la evolución de los precios de la tierra urbana, a partir del levantamiento y mapeamiento de las variables disponibles en los clasificados de terrenos en el principal diario de circulación local. La parte final del artículo busca analizar la estructuración del espacio urbano a partir de la dinámica de la actividad inmobiliaria, investigando el caso más específico de la Zona Oriental de la ciudad.

Palabras Clave: producción del espacio urbano, reestructuración urbana, mercado inmobiliario, renta de la tierra.

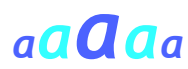

Revista da ANPEGE, v. 7, n. 7, p. 13-29, jan./jul. 2011

ISSN 1679-768 X c c 2003, Associação Nacional de Pesquisa e Pós-Graduação em Geografia. Todos os direitos reservados. 


\section{INTRODUÇÃO}

Desde algumas décadas a produção do espaço urbano, por meio do circuito imobiliário, assume função importante e dinâmica no modo capitalista de produção. Seja como condição, produto e meio desse processo (CARLOS, 1994), o espaço, sobretudo o espaço urbano, adquire um papel central, definidor da estruturação dos fluxos de capitais, bem como das formas e meios pelos quais estes se realizam enquanto valor, e se valorizam especulativamente. Mediante a fluidez do capital, principalmente nas últimas décadas, em que houve uma dinamização na sua mobilidade pelo globo, o processo assume expressões geográficas que transladam da escala local à escala do Estado-nação e à global, não necessariamente nessa ordem, mas a elas articuladas. Assim, a produção do espaço urbano, em seu sentido amplo, ganha um novo significado, para além de um simples reflexo da atividade econômica, mas como momento central e ativo da realização do capital, o qual pode tanto reordenar a atividade econômica, dinamizando as bases de sua produção, como também solapar as decisões econômicas e de investimento de setores inteiros da economia, obrigando uma reorientação nas bases produtivas e da reprodução social.

Esta pesquisa, aqui brevemente apresentada, ao analisar o mercado de terrenos urbanos, as frentes de expansão imobiliária e o papel dos agentes envolvidos no processo - aplicando-se ao estudo de caso da cidade de Londrina que tem passado por um momento de definição nas formas do ambiente construído, consolidando ainda sua estruturação urbana via novas incorporações imobiliárias -, propõe a apreensão do movimento do capital pelo espaço urbano, suas origens e as formas em que se realiza, ainda que referente especificamente a uma dada formação socioespacial. Faz elo então com o setor imobiliário à escala do Estado-nação e internacional, haja vista a presença de capitais estrangeiros nesse setor em Londrina, apesar da constante força dos capitais locais, e sua lógica de valorização ao longo das quatro últimas décadas que, inclusive, têm demandado hoje outras áreas de investimento em diferentes cidades e estados brasileiros.

Isso obriga a uma análise multiescalar centrada nos atores hegemônicos, no papel do poder público, seja em âmbito municipal, estadual ou federal e, principalmente, nos grandes grupos locais e externos, estruturantes do mercado imobiliário em Londrina, assim como também em outras cidades. Instigante é, para o caso dos grupos locais, a preferência por cidades de portes semelhantes, conforme pudemos atestar, não obstante sua centralização em determinadas cidades, reunindo diferentes empresas, embora todas elas articuladas direta e/ou indiretamente à construção civil, sob o comando de um mesmo grupo, orientadas, assim, por uma mesma gestão centralizada. Este aspecto, a meu ver, é central na discussão da territorialização desses grupos e na apreensão do processo espacial que catalisam ao se reproduzirem como tais, estendendo-se a outros espaços, aventando novas possibilidades de extração da mais-valia, da renda da terra e dos lucros advindos das atividades de incorporação imobiliária, de natureza contraditória, espacialmente expansiva e centralizadora no tocante ao seu comando.

Os resultados demonstram que o espaço assume um papel central e peremptório na reprodução do capital, na extração da mais-valia, na realização do valor de troca, e na geração de riqueza e do produto interno da cidade por meio da exploração de lucros fundiários e imobiliários, mormente em nossos dias, quando vemos uma aparente autonomização das bases financeiras do setor imobiliário, a ponto de, relativamente, ser convencionado como um capital particular com suas próprias lógicas de auto-valorização, e se impor como momento ativo na reprodução social e na política do espaço. Colocamos, então, em reflexão, a partir do estudo da valorização imobiliária e fundiária em Londrina, a contínua presença da produção do ambiente construído nos circuitos de reprodução capitalista, para além de uma simples etapa, mas, como um momento ativo da reprodução do capital em geral. 


\section{O EMBATE ENTRE ANTIGAS FORMAS E NOVOS PROCESSOS DE PRODUÇÃO DO ESPAÇO URBANO}

A propriedade privada da terra, sobretudo urbana, fonte de crises no capitalismo, obstáculo e, ao mesmo tempo, fundamento do modo de produção capitalista, vem, nos liames com a financeirização contemporânea de quase tudo, se transmutando, ou, à imagem e semelhança do capitalismo, assumindo conotações, talvez, descoladas de sua própria materialidade, mas não de sua essência [especulação], que é aquela de transformar dinheiro em dinheiro aumentado sem, antes, passar, necessariamente, pela produção da mercadoria. Lefebvre (2001, p. 73) fez interessantes observações em relação a um futuro não muito distante, em que o automatismo, numa face malévola, ao acometer e subordinar ruas, praças, monumentos, casas, trabalhadores, o intelecto humano, os homens e todas as suas atividades, e também o usuário, tornando-o impotente para proclamar o "valor de uso", mais que isso, a sequência dos fins, impotente para proclamar e autorizar o próprio "valor de troca", um conflito supremo, um limite, uma autocontradição do próprio capitalismo, que, por sua vez, não se ausenta na produção da cidade, mas a compõe.

O mercado de terras absorve todas as contradições fundamentais do modo capitalista de produção. Seu preço capta simultaneamente o caráter temporal da acumulação capitalista e o caráter específico dos valores de uso distribuídos no espaço. Renda e trabalho futuros estão em jogo, e o poder de monopólio da propriedade privada orienta os preços da terra e a capacidade de apropriação da renda conferida por esse poder, qual seja, a capacidade de desempenhar um papel ativo no processo de coordenação, estruturação e reestruturação da cidade, especificamente quando a terra é tratada como um ativo financeiro. A questão, porém, é que, metamorfoseada num ativo financeiro puro, quando inserida na lógica do sistema de crédito, elemento este estruturador do mercado financeiro a serviço da própria "valorização do valor", a terra está sujeita a todas as oscilações e problemas inerentes ao próprio sistema de crédito, ao mercado financeiro, e às convulsões causadas pela especulação, esta, por sua vez, também intrínseca a esse mercado e à própria essência da renda e da propriedade privada da terra para um outro fim qualquer que não aquele dado pelo seu valor de uso e/ou necessariamente por seu uso produtivo.

A partir de estudo de caso do mercado imobiliário da cidade de Londrina - $\mathrm{PR}$, e da compreensão da renda da terra como um mecanismo controlador da estruturação espacial da cidade e da dinâmica desse mercado, constata-se que o movimento de estruturação dos preços praticados no mercado imobiliário formal é corolário da dinâmica descrita no parágrafo anterior, e que existem mecanismos acionados pelos agentes deste mercado que, articulados aos seus propósitos e objetivos, direcionam e valorizam a expansão da malha urbana bem como a política e o planejamento à escala do município. No entanto, longe de se dizer que há um controle ou um equilíbrio, o traço monopolista presente no setor impõe tendência ao movimento de estruturação dos preços e à valorização e desvalorização seletiva de áreas da cidade, num continuum da dinâmica econômica observada à escalas do Estado-nação e à da conjuntura internacional no tocante ao circuito imobiliário e às novas formas de produção do espaço urbano.

Esse processo suscita a compreensão da (re)produção do espaço urbano à luz da dinâmica da acumulação capitalista e da noção de ajustes espaciais desenvolvida por Harvey, que também faz elo com teoria do desenvolvimento geográfico e desigual, herdada da teoria do desenvolvimento desigual e combinado, explicativa de como as formas geográficas se constituem e sustentam processos de acumulação, reprodução por espoliação e destruição de formas pretéritas do ambiente construído como um meio de realização do valor.

Londrina passou por profundas transformações espaciais nas duas últimas décadas, quando se destacou o circuito imobiliário que, além de alavancar o produto interno da cidade, substantivou o espaço urbano com novos produtos e intensificou os fluxos de capitais, dinamizando a crescente importância dos negócios imobiliários numa injustificada explosão urbana da cidade como uma máquina de crescimento urbano. Esse processo não é próprio apenas de Londrina, articula-se 
também à dinâmica atual do modo capitalista de produção em sua tessitura espacial, propósito da discussão a seguir.

\section{A DIALÉTICA DO DESENVOLVIMENTO GEOGRÁFICO DESIGUAL E O AJUSTE ESPACIAL: "SOLUÇÕES" EM TEMPOS DE CRISE OU A REESTRUTURAÇÃO ESPACIAL?}

Dando continuidade ao objeto deste artigo e ao leitmotiv da pesquisa como um todo, é necessário compreender, pela perspectiva da ordenação espaço-temporal e da expansão geográfica do capital, como esta última redefine, não só as tradicionais formas organizacionais da produção, mas a tessitura espacial da escala global à escala da cidade, inclusive dinamizando a produção dessa própria escala enquanto um produto e um "veículo" político das formas de expressão do capital e de seus constrangimentos e/ou rebatimentos (SMITH, 2000).

A partir da teoria da ordenação espaço-temporal de Harvey (1990), pode-se afirmar que a continuidade do processo de produção do valor leva a crises de sobre-acumulação, o que, essencialmente no âmago da lei da taxa declinante de lucros, exige, para o escoamento do excedente produzido e realização do valor, a expansão geográfica, mediante o que Harvey (2006) denomina de "ajustes espaciais" ou deslocamentos espaço-temporais. Toda essa dinâmica é sustentada pelos circuitos do capital e pela produção do espaço - Harvey usa a expressão ambiente construído - os quais, por fim, resultam no que ele tem denominado em várias obras (HARVEY, 1990, 2004a, 2004b, 2006, 2008) de desenvolvimento geográfico desigual, isto é, resumidamente, a contradição que resulta da oposição constante entre a tendência à diferenciação e a tendência à igualização (NOGUEIRA, 2009 , p. 92 e 93). Antes de prosseguir na teoria do desenvolvimento geográfico desigual, em sua relação com os "ajustes espaciais", realizaremos uma breve exposição das raízes da metateoria em questão - a lei do desenvolvimento desigual e combinado -, suas origens e desenvolvimentos.

A lei do desenvolvimento desigual, uma herança grega, legado da teoria marxista - rediviva pelas mãos de Trotsky -, a ponto de Ernest Mandel chegar a dizer que, com exceção da própria obra de Marx e da determinação econômica da luta de classes (LOWY, 1995, p. 79, COGGIOLA, 2004), nenhuma ideia de origem marxista foi tão amplamente difundida e assimilada desde há meio século, mesmo que raramente seja feita referência ao seu autor. Sua lógica deriva especificamente das tendências opostas, inerentes ao capital, para a diferenciação, mas com a simultânea igualização dos níveis e condições da produção.

Pertinentemente, na etapa de sua expansão mundial no século XX, sob a marca da desigualdade e da combinação, o capitalismo se afirmou como modo de produção dominante, destruindo formas pré-capitalistas também de modo desigual, penetrando em países com escasso desenvolvimento, mas que conservariam sua soberania nacional e territorial . Portanto, impõe-se contraditoriamente sobre a base da constituição do mercado mundial, encontrando sua expressão última em crises, revoluções e guerras (COGGIOLA, 2004, p. 21 a 23).

Retomando a contribuição de Marx à teoria, ao partir de observações iniciais de a Filosofia do Direito de Hegel, Harvey (2006, p. 99 e 100) observou que o capital cresce enormemente num lugar, numa única mão, porque foi, em outros lugares, retirado de muitas mãos. Trazendo para um contexto mais específico, o capital move-se para áreas onde a taxa de lucro praticada é mais alta afastando-se de áreas onde ela seja baixa, sendo seus movimentos sincronizados com o ritmo de acumulação e crise. "Mas o próprio processo de desenvolvimento leva à diminuição dessa taxa de lucro mais alta [...]", havendo, portanto, uma tendência à igualização da taxa de lucro e, embora isso tenha uma clara expressão geográfica, revela-se concretamente ao se analisar cada caso espacial (SMITH, 1984, p. 212).

$\mathrm{Na}$ esteira de uma geografia histórica do capitalismo, como produto da acumulação de capital, Harvey (2006, p. 117), com base especialmente no capítulo final do primeiro volume de O Capital - A Teoria Moderna da Colonização -, preconiza que, assegurado pela "dialética interna" 
do capitalismo, o processo do capital, "move-se em contradições constantemente superadas, mas, no momento exato, constantemente situadas" que, mediante a um recurso permanente ao "ajuste espacial", impõem certa "racionalização", reproduzindo-a, à "dialética interna" do capitalismo. O problema maior reside nas limitações desse recurso, e saber por quanto tempo a acumulação contínua pode ser sustentada, antes que crises geograficamente localizadas, ou que "crises de mudanças" nos fluxos de capital, unam-se a crises estruturais.

Harvey (2004b, p. 82 e 83) coloca a questão do desenvolvimento geográfico desigual de maneira bem clara e atual, ao argumentar que a circulação do capital em geral envolve mudanças de localização, definindo um conjunto de movimentos que, ao superarem a fricção imposta pela distância, fazem com que as atividades se agreguem ao espaço, resultando disso a divisão territorial e espacial do trabalho. Assim, "[...] a atividade capitalista produz o desenvolvimento geográfico desigual mesmo na ausência da diferenciação geográfica em termos de dotação de recursos e de possibilidades [...]", fatores que acrescentariam seu peso à lógica das diferenciações e especialização espaciais e regionais.

Harvey (2008, p. 125) é esclarecedor ao "ampliar" o uso da teoria do desenvolvimento desigual e combinado à luz da dinâmica mais atual do capitalismo com novos elementos circunscritos a um plano multiescalar - assim como o fizera Smith (1984) -, possibilitando articulações entre as escalas espaciais da produção. Para o autor, a atuação das forças de classes e corporações internas e externas ao Estado-nação, a predominância das ideias dominantes e seu poder sobre o encaminhamento da operacionalidade estatal em fases recessivas, a fuga de capitais em momentos de crises, a recusa em investir e a especulação financeira, ou ainda, a possibilidade de que essas crises sejam deliberadamente arquitetadas para facilitar a acumulação por espoliação, constituem a expressão mais nítida do desenvolvimento geográfico desigual. Assim, sendo este "[...]resultado da diversificação, da inovação e da competição (por vezes de tipo monopolista) entre modelos de governança nacionais, regionais e mesmo metropolitanos quanto o foi da imposição por algum poder hegemônico externo, como os Estados Unidos" (HARVEY, 2008, p. 125), propicia a compreensão do papel dos novos arranjos estruturais da economia capitalista em suas articulações com o - e a produção do - espaço geográfico.

À atuação das forças capitalistas da sociedade, Harvey (2004, p. 72), assim como Henry Lefebvre, submete a mobilização e o domínio do espaço como força produtiva peculiar a si mesma, protegendo continuamente seu poder, mediante esse mecanismo, de controlar e de produzir espaço.

É assim que, para Harvey, o capitalismo não pode sobreviver sem seus "ajustes espaciais", sem seu recurso à reorganização geográfica (em termos de expansão e em termos de intensificação) como solução parcial para suas crises e seus impasses, sem seu recurso ao desenvolvimento geográfico desigual e combinado, dispersando geograficamente a produção pelo mundo, ao mesmo tempo em que, centraliza o poder corporativo e a gestão de capitais, por meio de fusões, assunções agressivas de controle ou acordos de produção (entre empresas e corporações) que, conjuntamente, transcendem as fronteiras nacionais, controlam o espaço, tornando os lugares individuais cada vez mais vulneráveis às ordens produtivas e especulativas próprias da esfera do capital financeiro que, ultimamente, tem, se reproduzido e se valorizado por meio da produção do ambiente construído (HARVEY, 2004a, p. 92).

Fruto da competição capitalista, as crises, como produto das contradições internas do capitalismo, isto é, da reprodução ampliada do capital que faz com que haja uma tendência geral de a taxa de lucro declinar ao longo do tempo, relacionadas à produção e à absorção de excedentes de capital e trabalho, estão associadas à urbanização do capital, na medida em que o capitalismo, dinamicamente tecnológico e necessariamente expansionista, busca sempre novos mercados de consumo, transferindo os excedentes de capital e trabalho para a produção de infra-estruturas de uso individual e coletivo. Dessa maneira, capitais excedentes migram de um circuito da economia para outro. Entretanto, essa transferência não se dá sem problemas. 
No caso específico do circuito secundário (o imobiliário, fundos de consumo, capital fixo, infra-estrutura em geral), os investimentos são de longa duração e requerem expressivos montantes de capitais. Além disso, ainda há o problema do acesso de grande parte da população ao que é produzido nesse circuito, sendo, então, o Estado, chamado a participar como promotor, financiador e/ou regulador desse mercado, como é o caso da habitação. Valença (2008, p. 246) destaca que há o risco de se destruir vultosos investimentos do passado e, também, que investimentos do circuito primário (produção da maioria das mercadorias) requerem o investimento em capital fixo, inclusive no imobiliário. Não obstante, em momentos de crise, Valença (2008, p. 247) destaca que os capitais estão mais propícios a investir nos circuitos secundários e terciários, mesmo que com isso ocorra destruição de parte do capital fixo investido no passado, embora não seja essa a regra tácita.

Portanto, uma conclusão a que chega Valença (2008, p. 247 e 248), como um estudioso das obras de Harvey, é que o capital busca uma saída para crises de sobreacumulação, incluindo aí uma expansão geográfica muito mais associada ao processo de urbanização e às novas formas de regionalização do capital advindas da expansão do modo capitalista de produção, para além da acumulação primitiva discutida por Marx. E no que diz respeito ao circuito secundário, ele vai requerer capital fixo de toda ordem (infra-estrutura de uso individual e coletivo, investimentos em transportes, comunicação, fundos de consumo etc.), e aqui, acrescentamos, de acordo com Harvey (2004b, p. 139), que:

É também possível acumular no contexto de demanda efetiva estagnada se os custos dos fatores (terrenos, matérias-primas, produtos intermediários, força de trabalho) declinarem significativamente. $\mathrm{O}$ acesso a fatores mais baratos é, assim, tão importante quanto o acesso a mercados mais amplos para manter abertas as possibilidades de lucro.

Assim, o capitalismo sempre precisa se expandir geograficamente, buscando um elemento externo para se reorganizar, recorrendo ao desenvolvimento geográfico desigual (HARVEY, 2004a, p. 40). Então, a produção, o consumo e o uso do ambiente construído, ao promoverem a circulação do capital, comparecem também como uma expressão dos "fluxos de capital", constituindo-se fonte permanente de lucros para os capitalistas.

Isso não significa uma interpretação monolítica, posto que o pretendido seja, justamente, colocar em questão o aspecto crucial a que chegamos, ou seja, a compreensão de que, "como um meio de afastar a crise, ao menos temporariamente, o capital é retirado da esfera industrial" e, conforme demonstrou Harvey, “[...] há uma tendência ao capital ser deslocado para a produção do ambiente construído, onde as taxas de lucro permanecem mais altas e onde é possível, através da especulação, a apropriação de renda da terra [...]" (SMITH, 2007, p. 26).

Diante do exposto, em função do papel central que a atividade imobiliária assume em vários países, somos instados a investigar seu comportamento, suas bases de sustentação e reprodução, por meio da análise de sua autorrealização, recorrendo aos trabalhos de alguns estudiosos (TOPALOV, 1979; HARVEY, 1980; GOTTDIENER 1997; RIBEIRO, 1997; BOTELHO, 2007; FIX, 2007; CARLOS, 2008) os quais, embora de distintas maneiras, estão atrelados ao tema da produção imobiliária em geral.

Em texto de 1970, Reflexões sobre a política do espaço, Lefebvre (2008, p. 71), numa passagem que ficou muito conhecida, já afirmava que:

A mobilização das riquezas fundiária e imobiliária deve ser compreendida como uma das grandes extensões do capitalismo financeiro, desde um certo número de anos; a entrada da construção no circuito industrial, bancário e financeiro foi um dos objetivos estratégicos durante o último decênio. Isso é completamente lógico, completamente coerente na sociedade tal como ela é. Mais exatamente, esse circuito do imobiliário foi, durante muito tempo, um setor subordinado, subsidiário; pouco a pouco se tornou um setor paralelo, destinado à inserção no circuito normal da produção-consumo. Embora ele 
seja normalmente um setor compensatório, pode até tornar-se um setor principal se o circuito normal "produção-consumo" arrefecer, se houver recessão. Então, os capitais encontram no imobiliário uma espécie de refúgio, um território suplementar e complementar de exploração; em geral isso não dura muito tempo, é um fenômeno "malsão". (destaques nosso).

Lefebvre vai ainda mais longe ao ressaltar que, “[...] o 'imobiliário' e a 'construção' deixam de ser circuitos secundários e ramos anexos do capitalismo industrial e financeiro para passar ao primeiro plano, ainda que desigualmente (o que se refere à grande lei , bastante conhecida do desenvolvimento desigual)" (LEFEBVRE, 2008, p. 126).

As mudanças verificadas atualmente no circuito imobiliário obrigam-nos a relativizar algumas características destacadas na citação anterior, pois, embora tal circuito ainda não constitua um tecido coeso, processualmente, elas implicam na evolução das suas formas e meios de valorização e reprodução. Portanto, mais do que uma via de escoamento para o capital produtivo-industrial sobreacumulado, temos aqui, de acordo com Nogueira (2009, p. 15), a produção do ambiente construído, como um complexo de atividades, cuja autonomia relativa articula um sistema especializado de agentes e atividades econômicas, em torno da moderna propriedade imobiliária e dos lucros daí decorrentes, compreendidos no interior da urbanização capitalista em nossos dias, no contexto da dominância financeira e das novas formas e expressões da produção do espaço urbano, sob o domínio dos agentes hegemônicos que estruturam e reestruturam áreas inteiras de cidades incompletas.

Em relação à renda da terra como mecanismo de divisão social do espaço, é fundamental saber que a partir dela se configuram os preços fundiários, e que sobre ela estão quantificados os movimentos de captação da mais-valia materializada na mercadoria terra urbana - esta que detém a propriedade de reter valor -, isto é, a base elementar do processo sobre a qual se manifestam formas fenomênicas que, nem por isso, deixam de ser importantes à análise e à evidência empírica e tampouco deixam, por essa razão, de ser concretamente explicativas em si, porque se trata de uma lógica que diz respeito ao modo capitalista de produção e de suas formas de valorização e captação do excedente produzido pela sociedade.

\section{PROPRIEDADE PRIVADA, RENDA DA TERRA E MERCADO DE TERRAS NA CIDADE DE LONDRINA-PR}

A incorporação da terra à malha urbana londrinense, desde os primórdios da ocupação da região pela Companhia de Terras Norte do Paraná, assinala, historicamente, o surgimento do mercado de terrenos urbanos em Londrina, o qual foi impulsionado, sobretudo, pela autonomização relativa entre produção e circulação da mercadoria terra urbana. Nessa fase inicial, o corretor de imóveis adquire importância fundamental já que não é mais preciso adquirir a mercadoria para transformá-la em dinheiro, permanecendo, portanto, a terra urbana na esfera do "capital produtivo fundiário". Assim, o produtor dessa mercadoria não precisa imobilizar parte de seu capital na esfera mercantil, enquanto o atendimento da demanda por espaço urbano ocorre mediado pelo desdobramento de um importante e eficiente mecanismo de valorização do "capital fundiário", notavelmente aprimorado, tanto nas formas de produção quanto de circulação, já em meados da década de 1950 (RAZENTE, 1984, p. 248).

O desenvolvimento desse setor, no norte do Paraná, vis-à-vis à necessidade de expansão do próprio capital acumulado a partir dos excedentes da lavoura cafeeira - internos e externos à cidade -, reflete a lógica dos interesses dos agentes produtores do espaço urbano: o proprietário da gleba, como aquele que compra a força de trabalho, "urbaniza" o espaço e obtém, no momento da realização da mercadoria, a mais-valia gerada no processo produtivo, além da renda da terra; o capital comercial, que exige sua remuneração como taxa de lucro; as diferentes formas de apropriação da terra pelo proprietário, que, ao reter a mercadoria fora do mercado, evita a diminuição do seu tempo de circulação, retarda a extração da mais-valia e limita a acumulação no setor, mas, por 
outro lado, evita a queda do preço, realimentando novos circuitos de produção, imprimindo novos traços à cidade, constituindo-se assim novas áreas aptas ao processo de valorização (RAZENTE, 1984, p. 248 e 249).

De acordo com Razente (1984, p. 250), em Londrina, este movimento de valorização dos terrenos urbanos teve sua fase de aceleração iniciada a partir de 1943 e estendendo-se até o início dos anos 1960, quando, em 1964, novos movimentos estruturais vão definir outros rumos às formas de valorização da terra urbana, com a promoção estatal da habitação. Razente $(1984$, p. 259) ainda afirma que, ao se afastar da esfera agrícola, o capital, dirigido pela possibilidade de reprodução intensa no setor imobiliário, introduzia-se metaforicamente como capital fundiário, o que na verdade, devia-se muito mais ao seu potencial de reprodução como capital fundiário do que pela eventualidade de baixa real nas taxas de lucro agrícolas, já que as mudanças ocorridas no uso da terra permitiam uma maior obtenção, e em menor tempo, da fração da mais-valia, acelerando ainda mais sua reprodução ampliada.

A ocupação do espaço urbano londrinense nesse período, foi determinada pela alavanca da acumulação promovida pela economia cafeeira, representando os interesses do capital agrícola e tendo como condicionantes, expressão e sentido a força de trabalho, tanto no campo quanto na cidade, a aglomeração dos meios necessários à produção e reprodução social, a presença de um poder público local permissivo e parcial, bem como o estabelecimento de relações sociais capitalistas e de um padrão de acumulação articulado em nível regional, nacional e internacional (RAZENTE, 1984, p. 260).

Segundo Razente (1984, p. 271), a década de 1960 configura-se um momento de inflexão, divisor de águas no mercado de terrenos urbanos, pois que foi marcada, sobretudo, por um processo de estagnação no crescimento e na valorização fundiária, não acompanhando sequer os altos índices inflacionários do período, com uma nítida tendência à nivelação dos preços fundiários em toda a cidade. Também, nessa época, a acumulação de capital na cultura cafeeira estava em franco declínio e as bases da acumulação preparavam-se para uma transição às atividades agroindustriais. Assim, a captação da mais-valia e dos sobrelucros fundiários precisavam reduzir seu ímpeto por um breve momento, para ressurgir em meados da década de 1970.

Edificar um novo padrão de reprodução do capital investido no setor imobiliário a partir de novas bases de acumulação e de mudanças significativas nas estruturas produtivas regionais, além das transformações estruturais e institucionais correlatas ao setor imobiliário e à construção civil, foi a característica da década de 1970, quando se imprimiu uma "nova" configuração econômica e socioespacial à cidade (RAZENTE, 1984, p. 275). Marcada pelo aprofundamento da intervenção estatal nas questões fundamentais à reprodução da força de trabalho e às exigências do padrão de acumulação capitalista, o período em questão resultou, segundo Razente (1984, p. 277):

na produção do espaço urbano pela fração do capital fundiário, nas áreas periféricas da cidade; na produção do espaço pela promoção estatal da habitação, voltado à reprodução da força de trabalho; na organização do espaço produtivo para a reprodução do capital industrial;

na articulação de todas estas instâncias, permeadas pela gestão do espaço urbano como um todo, através de sua utilização/ocupação.

Dessa maneira, o padrão de acumulação orientou a ação do poder público local a fornecer a alavanca para o capital industrial emergente na cidade, resultando na realocação espacial das zonas industriais, afastando-as das antigas áreas próximas ao centro comercial da cidade, medida tomada devido à reestruturação espacial que acometia esse setor, bem como a políticas setoriais e, ainda ao preço da terra que, então, já tornava desinteressante a presença de áreas industriais próximas aos bairros residenciais. No entanto, sob os auspícios da política hegemônica e centralizadora do período, tal projeto viu-se barrado. Inversamente às prioridades locais de acumulação de capital, os mecanismos operacionais do Banco Nacional da Habitação relegaram a segundo plano o projeto 
industrializante para Londrina. A ação governamental foi dirigida à organização do espaço urbano, gerando um aprofundamento das questões urbanas, com a valorização seletiva da cidade a partir de investimentos públicos, financiados pela força de trabalho (RAZENTE, 1984, p. 299).

Por essa razão, na década de 1970, a evolução dos valores fundiários em determinadas áreas atingiu índices acima da inflação, que se mantiveram até 1976. Contudo, teve início, a partir desse ano e durante toda a década de 1980, uma redução na amplitude dos valores no mercado fundiário. No ano de 1976 também ocorreu o auge dos negócios com terrenos e lançamentos de novos loteamentos, que só viria a encontrar paralelo novamente em fins dos anos 1990, quando novos processos entraram em cena no circuito imobiliário à escala nacional e também local.

O comportamento do mercado da terra urbana na cidade de Londrina refletiu os momentos de estagnação e aceleração econômica vivenciados no país, funcionando também como um mecanismo de fuga de capitais desvalorizados que, subsequentemente, vieram a se valorizar nesse mesmo mercado, aquecido pela dinâmica imobiliária impulsionada na cidade. Isso se deu num segundo momento, em fins da década de 1990 e, principalmente durante a década de 2000, quando os lucros aviltantes da atividade imobiliária compensaram a valorização dos estoques fundiários em paralelo ao crescimento dos investimentos em incorporações imobiliárias, sobretudo, daquelas destinadas aos segmentos mais capacitados, demandantes, por exemplo, da autosegregação dos condomínios horizontais e verticais de alto padrão. A materialização da valorização imobiliária nestas últimas formas reflete a potência do valor originado já num momento anterior, específico ao mercado de terras que, dialeticamente, estrutura o padrão de acumulação - por meio da produção do ambiente construído destinado neste caso ao habitat - e a expansão urbana na cidade. Este primeiro fenômeno da valorização do espaço urbano, conforme explica Harvey (2004b, p. 139), é o que nos chama atenção neste trabalho, para o qual dirigiremos nossos esforços na sequência do texto, focando a dinâmica do mercado de terrenos urbanos da última década.

Em nossa dissertação de mestrado analisamos as ofertas totais de terrenos no principal jornal de circulação local - Folha de Londrina - durante quatro anos, a saber: 2000, 2004, 2005 e 2009. A opção por esses anos levava em conta a análise mais específica da reestruturação espacial da Zona Leste da cidade, que começou a ganhar ímpeto a partir de 2005 (AMORIM, 2010), com o anúncio da construção de um complexo comercial, cultural e empresarial na área e com o início das obras no campus da Universidade Tecnológica Federal do Paraná. No entanto, nos ateremos à conjuntura verificada nos anos de 2000 e 2009, mais significativos, objetivos e demonstrativos da reestruturação espacial da dinâmica imobiliária em Londrina.

\section{REESTRUTURAÇÃO DO ESPAÇO URBANO PELA VALORIZAÇÃO DIFERENCIAL DA TERRA: PREÇO, VOLUME DE OFERTAS E INTERMEDIAÇÃO EMPRESARIAL}

O volume de ofertas de terrenos nos classificados de imóveis do jornal Folha de Londrina, além de constituir uma amostra confiável, mostrou-se suficientemente abrangente para toda a cidade, uma vez que centraliza a maior parte de anúncios desse tipo. No entanto, devemos ter em conta sempre que estamos lidando com um mercado no qual a disponibilidade de informação não é perfeita, e as expectativas de sobreganhos acima da média é um fator que nos põe diante de um dos mecanismos que nos afastariam dos preços médios dispostos pela cidade. Além dessa expectativa, há também outros aspectos que devemos considerar quando analisamos classificados de jornal, por exemplo, a possibilidade de os preços de ofertas, informados no momento inicial, diferirem dos que podem vir a se consolidar no ato final da negociação. Portanto, por comportar essa "expectativa", serão sempre maiores que os preços médios praticados num determinado loteamento ou mesmo num bairro da cidade, e maiores também que o preço final que se realiza no ato da venda do bem de raiz.

Na Tabela 1, na primeira linha, logo abaixo dos anos, dispomos o volume das ofertas totais anunciadas no período. Já na segunda linha, constam somente aquelas que ocorreram durante o período 
pesquisado sem, no entanto, serem computadas as repetições. Na frente dos meses, apresentamos o volume total de todas as ofertas anunciadas, procurando então aí demonstrar sua evolução mensal.

Tabela 1: Londrina. Volume de ofertas totais de terrenos nos classificados do jornal Folha de Londrina. 2000, 2004, 2005 e 2009

\begin{tabular}{|c|c|c|c|c|c|}
\hline \multicolumn{2}{|c|}{ ANOS: } & 2000 & 2004 & 2005 & 2009 \\
\hline \multicolumn{2}{|c|}{$\mathrm{N}^{\mathrm{o}}$ de ofertas totais anunciadas } & 1859 & 3542 & 4410 & 3958 \\
\hline \multicolumn{2}{|c|}{$\mathrm{N}^{\circ}$ de ofertas totais reais } & 1278 & 1811 & 2103 & 1009 \\
\hline \multirow{12}{*}{$\begin{array}{l}\stackrel{\tilde{D}}{\mathrm{e}} \\
\sum^{\infty}\end{array}$} & Janeiro & 109 & 107 & 285 & 264 \\
\hline & Fevereiro & 151 & 262 & 337 & 382 \\
\hline & Março & 88 & 201 & 422 & 360 \\
\hline & Abril & 130 & 294 & 421 & 356 \\
\hline & Maio & 184 & 243 & 337 & 304 \\
\hline & Junho & 117 & 375 & 368 & 315 \\
\hline & Julho & 165 & 323 & 434 & 340 \\
\hline & Agosto & 195 & 358 & 393 & 318 \\
\hline & Setembro & 198 & 338 & 326 & 349 \\
\hline & Outubro & 208 & 308 & 380 & 331 \\
\hline & Novembro & 170 & 352 & 372 & 316 \\
\hline & Dezembro & 167 & 380 & 334 & 323 \\
\hline
\end{tabular}

Fonte: Folha de Londrina - Classificados - 2000, 2004, 2005 e 2009.

Organização: AMORIM, Wagner Vinicius.

Em relação à distribuição dessas ofertas pelas cinco Zonas da cidade, pudemos constatar, com base na Tabela 2, que aquelas de maior destaque ao longo dos quatro anos foram, para o ano 2000, as Zonas Sul e Leste; para o ano de 2004, Oeste, Sul e Leste; situação que se repete para o ano de 2005; e, finalmente, para o ano de 2009, as Zonas Leste, Oeste e Norte.

Tabela 2: Londrina. Volume de ofertas totais de terrenos nos classificados do jornal Folha de Londrina segundo as Zonas Urbanas. 2000, 2004, 2005 e 2009

\begin{tabular}{l|c|c|c|c|c|c|c|c}
\hline \multirow{2}{*}{ ZONAS } & \multicolumn{2}{|c|}{2000} & \multicolumn{2}{c|}{2004} & \multicolumn{2}{c|}{2005} & \multicolumn{2}{c}{2009} \\
\cline { 2 - 9 } & abs. & rel. & abs. & rel. & abs. & rel. & abs. & rel. \\
\hline Centro & 169 & 13,28616 & 175 & 9,798432 & 196 & 9,386973 & 104 & 10,42084 \\
\hline Leste & 286 & 22,48428 & 431 & 24,13214 & 493 & 23,61111 & 257 & 25,7515 \\
\hline Norte & 245 & 19,26101 & 293 & 16,40538 & 355 & 17,00192 & 210 & 21,04208 \\
\hline Oeste & 253 & 19,88994 & 448 & 25,08399 & 538 & 25,76628 & 236 & 23,64729 \\
\hline Sul & 319 & 25,07862 & 439 & 24,58007 & 506 & 24,23372 & 191 & 19,13828 \\
\hline Total & 1272 & 100 & 1786 & 100 & 2088 & 100 & 998 & 100 \\
\hline
\end{tabular}

Fonte: Folha de Londrina - Classificados - 2000, 2004, 2005 e 2009.

Organização: AMORIM, Wagner Vinicius.

É preciso considerar que a concentração do volume de ofertas se dá em áreas específicas dessas Zonas, não se distribuindo homogeneamente para o conjunto das zonas inteiras. É o caso das Zonas Sul e Oeste, em cujos limites estão concentradas as ofertas, exatamente no sentido sudoeste. No caso da Zona Leste, elas também se referem a determinadas áreas, situadas num vetor de desenvolvimento ali imobiliário existente. Já a Zona Norte vem se destacando mais recentemente com o volume de ofertas de terrenos, o que se deve à subcentralidade urbana que esta área tem desenvolvido, decorrente daí a valorização da terra vinculada a este processo mais específico. 
A Figura 1 apresenta a espacialização das variáveis coletadas, demonstrando o volume de ofertas de terrenos para os anos de 2000 e 2009, em metros quadrados e em reais, conforme os classificados. É notável a valorização preço da terra urbana que se depreende dos quatro mapas apresentados, embora existam aí fatores, tais como a inflação, que devem ser levados em conta para compreender como evoluiu o preço das mercadorias no modo capitalista de produção.

De todo modo, a análise dos mapas apresentados na Figura a seguir demonstra uma maior equalização do volume de ofertas de terrenos em 2009, em comparação com o quadro apresentando no ano de 2000, embora se verifique a valorização ainda concentrada a sudoeste.

Em 2009, o mercado imobiliário, gerido pela iniciativa privada, havia se diversificado, com empreendimentos em distintas áreas da cidade e dirigidos a diferentes segmentos, ofertando produtos imobiliários socioeconomicamente segmentados e espacialmente segregados. Nesse período, após um reordenamento que ocorrera no setor, o mercado imobiliário se concentrou nas parcelas da população de maior renda, voltando-se aos grandes empreendimentos imobiliários, sobretudo, à verticalização residencial de luxo e aos condomínios horizontais que, em Londrina, alternam-se como os produtos imobiliários mais demandados por esses segmentos sociais. Embora mais recentemente o mercado de terrenos em condomínios horizontais tenha apresentado um arrefecimento, é significativo o nível de capitalização alcançado pelas construtoras locais (BERGAMASCO, 2003).

A constatação da dinâmica desse mercado, confirmada pelos próprios sindicatos do setor (Sindicato dos Corretores Imobiliários de Londrina e Sindicato da Indústria da Construção Civil no Norte do Paraná), reforça a ideia da mobilidade temporal e espacial do par valorização/desvalorização imobiliária orquestrada na cidade, ao longo da última década.

De acordo com Jaramillo González (2009, p. 99 e 100), o movimento de expansão do capital privilegia, num primeiro momento, certos ramos e setores cujas características iniciais lhe são mais favoráveis, em relação a outras atividades que oferecem mais obstáculos. A indústria da construção é um desses ramos em que o capital precisa vencer uma série de barreiras para se impor, sendo, portanto, o processo de penetração das relações capitalistas nesse setor ainda inacabado e pouco desenvolvido em muitas formações sociais.

O período excepcionalmente longo de rotação do capital no setor, somado ao período igualmente longo de circulação do produto imobiliário no mercado, se traduz numa falta de incentivo à penetração do capital no ramo porque, se de um lado afeta a taxa de lucro - ao elevar o preço do produto, restringindo a escala de operação das empresas -, de outro, exige para o processo produtivo uma acumulação prévia de capital mais elevada que em outros setores da economia. Aqui, a presença da propriedade privada da terra é componente chave, embora a experiência sob o capitalismo tenha demonstrado que não existe um mecanismo de ajuste interno que acople o fluxo de terras ao ritmo da acumulação no setor da construção. Porém, conforme afirma Jaramillo González (2009, p. 102), e a partir da realidade por nós estudada na cidade de Londrina, a propriedade territorial urbana tem se erigido como um meio de acumulação de capital inicial. Assim, o movimento secular ascendente dos preços da terra urbana, além de capitalizar as bases do setor, amortece o efeito das flutuações nas condições de acumulação no ramo - razões do seu atraso tecnológico -, reduzindo os riscos aos capitalistas que se lançam no setor, e compensando o investimento em face das amplitudes existentes nesse mercado.

A concentração da propriedade privada da terra, à revelia da concorrência e de corte monopolista, possibilita o controle dos preços praticados, bem como a estruturação do espaço urbano mediante as práticas dos agentes imobiliários de certa forma articulados à classe dos proprietários. Segundo o Instituto de Pesquisa e Planejamento Urbano de Londrina (IPPUL) a concentração fundiária é bastante flagrante no município. Saber até que ponto e em que medida os proprietários fundiários definem os rumos da estruturação espacial da cidade escaparia às possibilidades de nossa pesquisa, no entanto, os dados apresentados na Tabela 3 sugerem nítidos contornos da concentração da propriedade da terra. 

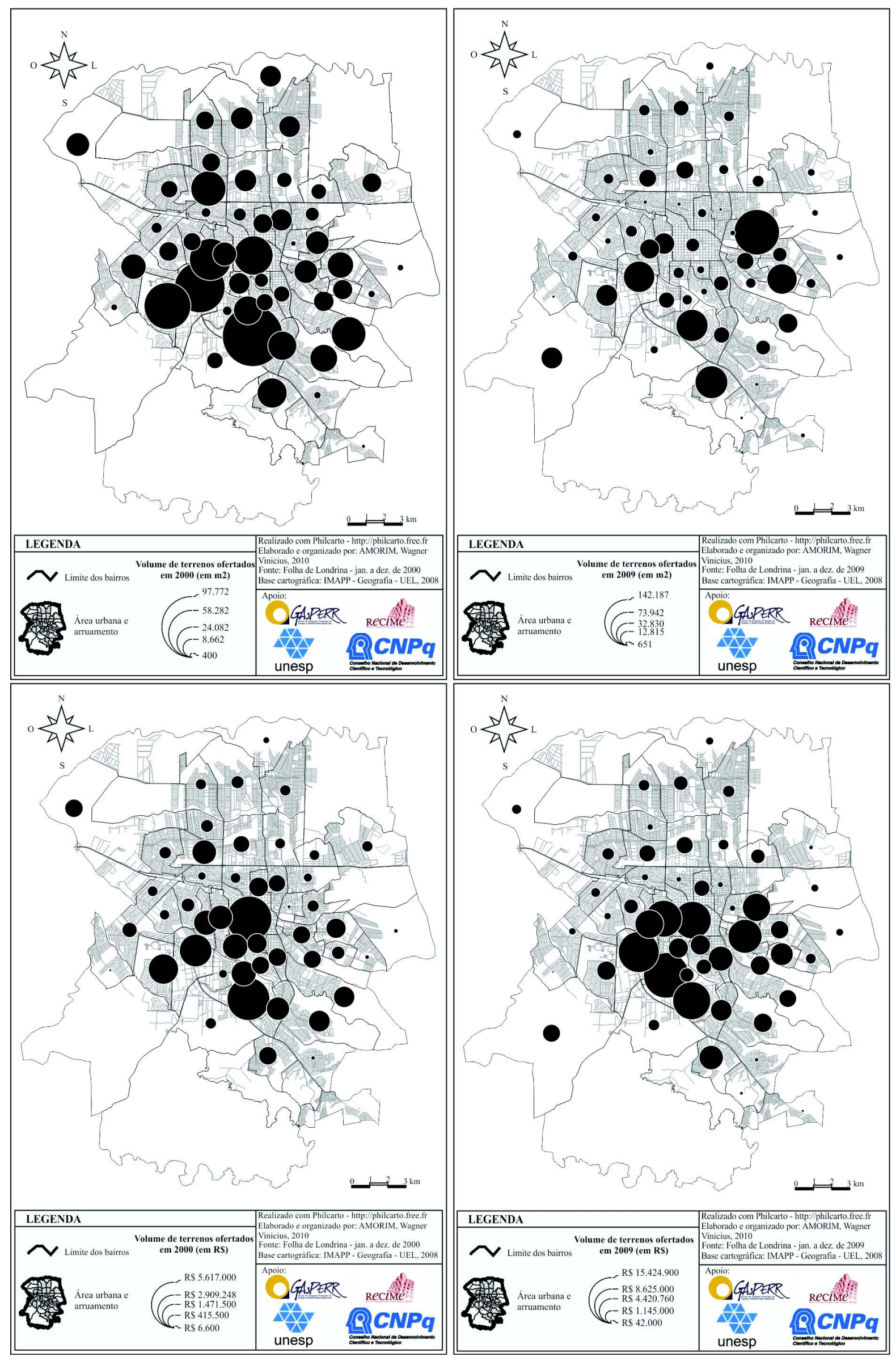

Figura 1 - Londrina. Volume total de ofertas de terrenos em metros quadrados e em reais. 2000 e 2009 
Tabela 3: Londrina. Classes de tamanhos dos terrenos vazios no município de Londrina- 2010

\begin{tabular}{|l|r|r|}
\hline CLASSES DE TAMANHO EM M & \\
\hline Até 1000 & VALOR ABSOLUTO $\left(\mathrm{EM} \mathrm{KM}^{2}\right)$ & $\%$ \\
\hline De 1000 a 5000 & 7,74 & 6,95 \\
\hline De 5000 a 10000 & 3,75 & 3,37 \\
\hline Acima de 10000 & 2,29 & 2,00 \\
\hline Total & 97,46 & 87,61 \\
\hline
\end{tabular}

Fonte: Nascimento, Moreira e Castro (2010).

A partir dos levantamentos dos classificados de oferta de terrenos em 2000, 2004, 2005 e 2009, no principal jornal da cidade, apreendemos a estruturação do preço da terra urbana e suas articulações com os movimentos estruturais locais da valorização imobiliária. Com as coletas de todos os anúncios de terrenos, analisadas um domingo ao mês, e todos os meses do ano, adotando-se alta padronização quando da digitação dos dados nas planilhas e a exclusão das linhas duplicadas, pudemos constatar o preço médio dos terrenos, dividindo a soma do preço em reais pela soma do volume em metros quadrados para cada bairro informado. Por fim, para a distribuição das classes de preços nos mapas apresentados na Figura 2, a seguir, utilizamos a técnica de amplitude de classes (produto do número de valores pelo número de classes), demonstrando classes com o mesmo número de unidades espaciais (cinco e/ou seis ocorrências para cada classe), mantendo-se as proporções, situando-se as médias intraclasses e minimizando-se o desvio padrão.

Com base no trabalho realizado, entendemos que o mercado de terrenos urbanos, sobretudo num espaço urbano não metropolitano, possui dimensões que permitem a agentes articulados entre si, e que compartilham expectativas similares, o exercício de um grande controle sobre a expansão da malha urbana e da valorização fundiária, ainda que às vezes também possam divergir no tocante aos sentidos e orientação das práticas espaciais aí implicadas, abrindo assim um leque de conflitos entre capitais. Contudo, a homogeneidade das práticas e das ações dos agentes imobiliários, quando vislumbradas em sua dimensão espacial, revelam o conteúdo classista - não isento de questionamento - e, sobretudo, socioespacialmente segregacionista e seletivo.

A década analisada, como efeito da dinâmica imobiliária das décadas precedentes, revela a concentração da valorização fundiária na cidade em determinadas áreas e vetores de desenvolvimento imobiliário. Esse movimento se deu, historicamente, no sentido sudoeste da área central, havendo aí marcos importantes como, por exemplo, as construções do Lago Igapó, em meados da década de 1950, do centro cívico na década de 1970 e, principalmente, a do shopping Catuaí, nos anos 1990, consolidando este vetor de valorização imobiliária, com o posterior surgimento dos condomínios horizontais e de edifícios residenciais de luxo às margens do mesmo Lago Igapó. Nas entrevistas realizadas, constatamos que muitos proprietários de terras nessas áreas constituíram-se em agentes da valorização e da construção de um marketing para a área, transformando-a hoje no metro quadrado mais caro da cidade. Da mesma forma, a dimensão espacial assumida pela valorização corrobora a ideia de que ela é espacialmente segregada, seletiva e concentrada e, quando muito, polariza-se em torno de algumas áreas.

Em meados da década de 2000, quando muitas empresas encontravam-se suficientemente capitalizadas para iniciarem um processo de crescimento e expansão da atividade imobiliária em Londrina, sobretudo daquela voltada aos condomínios e à verticalização residencial, o aumento do preço da terra, no âmbito das chamadas "âncoras imobiliárias", funcionou como uma blindagem a determinados tipos de práticas socioespaciais não desejados pelo mercado. Se num primeiro momento, o baixo preço da terra funciona como um fator de capitalização e ascensão das empresas, numa etapa seguinte, torna-se um mecanismo de valorização dos ativos e de realização do valor presente na mercadoria terra. $\mathrm{O}$ crescimento das principais empresas do mercado, bem como o nível dos novos produtos imobiliários ofertados num contexto de alto desempenho foram tão re- 


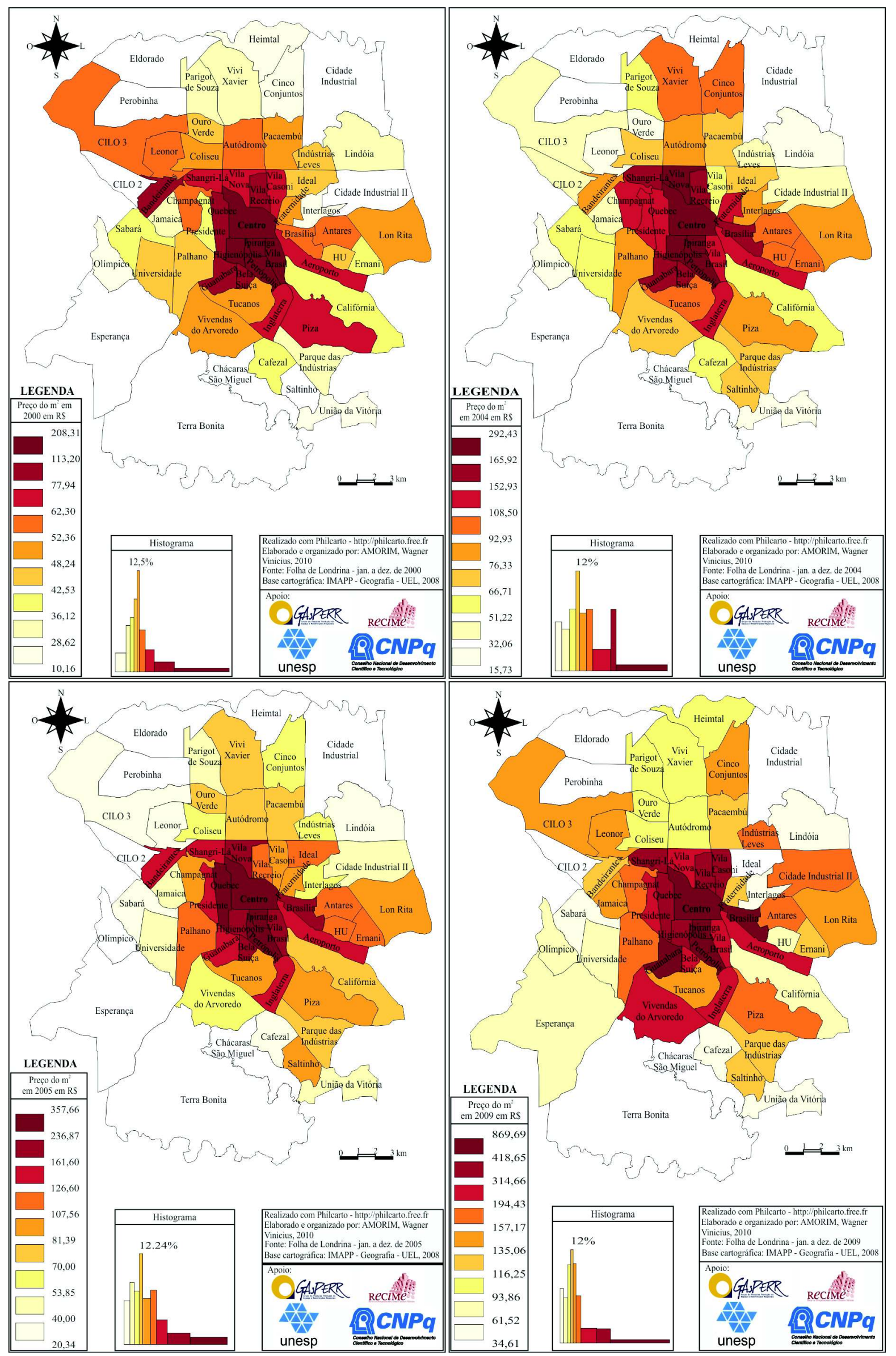

Figura 2 - Londrina. Preço médio de terrenos ofertados nos classificados. 2000, 2004, 2005 e 2009 
levantes, que atividades menos capitalizadas, como investimentos em novos loteamentos, não se mostravam tão lucrativos quanto a imobilização de capitais em outros produtos imobiliários, para os quais havia uma demanda altamente capacitada. A inadimplência dos mercados populares e a volta dos pacotes governamentais destinados à habitação também funcionaram como arrefecedores do mercado de terrenos, estimulando cada vez mais as empresas a se concentrarem na verticalização e nos condomínios horizontais.

No ano de 2004, dos 53 bairros informados no primeiro mapa, apenas 16 apresentaram real valorização imobiliária, quando verificado o preço deflacionado, isto é, retirando-se do preço informado em 2004 aquele aumento provocado apenas pela inflação vigente no período . Porém, nenhum deles registrou um aumento superior a $50 \%$ em relação à inflação vigente. Em 2005, em continuidade à tendência apontada em 2000, só 18 bairros apresentaram aumentos situados acima da inflação vigente no período 2000-2005. Alguns picos apresentaram índices até mesmo acima de $100 \%, 80 \%$ e $66 \%$ de aumento em relação à inflação, destacando-se então altos preços na Zona Leste da cidade, em função das expectativas que começavam a surgir devido à construção de um futuro shopping center na área.

Em 2009, no entanto, a situação se inverte: em apenas 13 bairros o aumento do preço da terra não alcançou a inflação aferida no período, ocorrendo maior valorização das áreas, ao contrário dos períodos precedentes analisados. Nesse ano, 10 bairros apresentaram índices acima de 100\% em relação ao crescimento inflacionário, chegando alguns casos a mais de $345 \%, 213 \%$ e $168 \%$. Esses dados, além de demonstrarem um momento de consolidação da renda da terra enquanto fator de capitalização dos ativos imobiliários, revelam também a expansão recente dos negócios imobiliários na Zona Leste, onde se instalou a Universidade Tecnológica Federal, bem como teve início a construção de um complexo cultural e comercial, o Marco Zero, onde também serão construídos o Shopping Boulevard e o Teatro Municipal, e, ainda, foram lançados um hipermercado e vários empreendimentos residenciais verticais e horizontais destinados à famigerada "classe média". De todo modo, os picos no preço da terra continuam concentrados no sentido sudoeste e na área central, confirmando práticas socioespaciais fragmentárias e social e historicamente orientadas.

\section{CONSIDERAÇÕES FINAIS}

A análise da produção do espaço urbano em Londrina, a partir da estruturação econômica do preço da terra articulada a ações de agentes dessa produção, nesse caso o poder público e o setor privado, identifica a relação dialética existente entre a morfologia urbana e as forças econômicas e sociais estruturantes desses espaços. Não apenas um reflexo ou um produto dos interesses econômicos no capitalismo, o espaço urbano comporta-se como um meio, um modo e uma condição através dos quais as forças capitalistas se movimentam e agem, em embate conflituoso com a sociedade civil, ou mesmo com o espaço herdado enquanto uma rugosidade portadora de inércia dinâmica, desenvolvendo sua necessidade de sempre produzir espaço, como uma condição à sua própria sobrevivência e, ao mesmo tempo, ao amplo processo de reprodução do capital em geral.

Em seminário proferido em 1972, Lefebvre (2008, p. 57) afirmou que as contradições do espaço social advêm do conteúdo prático e social e, especificamente, da essência do capitalismo. Tal espaço pretende-se racional quando é comercializado, parcelado, e vendido em lotes. Assim sendo, simultaneamente global e pulverizado, o espaço parece lógico ao mesmo tempo em que é extremamente recortado, expondo contradições que explodem no plano institucional (LEFEBVRE, 2008, p. 57). Nessa perspectiva, destaca Lefebvre (2008, p. 57), a burguesia dispõe de um duplo poder: além da generalização da propriedade privada da terra, detém a globalidade e o conhecimento estratégico da ação do Estado, bem como a dos principais agentes promotores do espaço urbano.

O espaço homogêneo-fraturado produzido pelo promotor imobiliário (LEFEBVRE, 2008, p. 49), herdeiro de formas conteúdos pretéritos, que interagem com o sujeito da produção e com 
o padrão de acumulação, engendra, paralelamente, uma lógica que vai embutida na dinâmica da acumulação e da valorização desses capitais.

Aqui, esta "simbiose" entre o espaço, o capital e seu processo de acumulação/valorização implica num vigoroso modus operandi da reprodução ampliada do capital, ao passo que o próprio espaço, assumindo estatuto ontológico, coloca-se diante da ação capitalista e da sua busca desenfreada por lucros ou renda fundiária, seja qual for a fonte, visto que os agentes capitalistas do setor imobiliário ainda não compõem tecido coeso, muitos ainda consentindo com práticas já consideradas arcaicas por outros segmentos mais desenvolvidos da atividade. Pela primeira razão, a renda da terra na cidade se mostra viva e dotada de significado para o entendimento da evolução físico-territorial da malha urbana, bem como para a compreensão da lógica de reprodução do espaço sob o capitalismo contemporâneo. Pela segunda razão, a compreensão de uma realidade concreta, pontualmente objetada, põe-nos a refletir sobre as assincronias que medeiam as relações de produção sob o capitalismo, seja porque ele é desigualmente desenvolvido no tempo e no espaço, seja porque é imbuído de ordens e lógicas que correspondem a diferentes e (i)limitados níveis da potência da acumulação criadora/destruidora/reestruturadora do capital.

\section{REFERÊNCIAS BIBLIOGRÁFICAS}

AMORIM, Wagner V. Produção capitalista da cidade e poder público local: a valorização imobiliária e a reestruturação urbana em Londrina - PR - Brasil. La planificación territorial y el urbanismo desde el diálogo y la participación. Actas del XI Coloquio Internacional de Geocrítica, Universidad de Buenos Aires, 2-7 de mayo de 2010. Disponível em: http:/www.filo.uba.ar/contenidos/investigacion/institutos/geo/geocritica2010/627.htm. Acessado em 30 de mar. de 2011.

BERGAMASCO, Fernando L. Estudo da competitividade das empresas de construção civil de Londrina. 2003. Dissertação de Mestrado. (Mestrado em Administração). Programa de Pós-Graduação em Administração do Departamento de Administração da Universidade Estadual de Londrina, 2003.

BOTELHO, Adriano. O urbano em fragmentos. A produção do espaço e da moradia pelas práticas do setor imobiliário. São Paulo: Annablume; FAPESP, 2007.

CARLOS, Ana F. A. A (Re)Produção do Espaço Urbano. São Paulo: Edusp, 1994.

CARLOS, Ana F. A. De la "geografía de la acumulación" a la "geografía de la reproducción": un diálogo con Harvey. Scripta Nova. Revista Electrónica de Geografía y Ciencias Sociales. Barcelona: Universidad de Barcelona, 1 de agosto de 2008, vol. XII, No 270 (143). Disponível em: http://www.ub.es/geocrit/sn/sn270/sn-270-143.htm. Acessado em 15 de dez. de 2009.

COGGIOLA, Osvaldo. Trotsky e a lei do desenvolvimento desigual e combinado. Novos Rumos, São Paulo, Ano 19, No 42, p. 4-23, 2004. Disponível em: http://www.institutoastrojildopereira.org.br/novosrumos/ file_42/trotski.pdf. Acessado em 24 de dez. de 2009.

FIX, Mariana. São Paulo cidade global. São Paulo: Boitempo, 2007.

GOTTDIENER, Mark. A Produção Social do Espaço Urbano. 2a ed. São Paulo: Edusp, 1997.

HARVEY, David. A Justiça Social e a Cidade. São Paulo: Hucitec, 1980.

HARVEY, David. Los limites del capitalismo y la teoria marxista. México: Fondo de Cultura Económica, 1990.

HARVEY, David. A produção capitalista do espaço. $2^{\mathrm{a}}$ ed. São Paulo: Annablume, 2006.

HARVEY, David. Espaços de Esperança. São Paulo: Ed. Loyola, 2004a.

HARVEY, David. O Novo imperialismo. São Paulo: Ed. Loyola, 2004b.

HARVEY, David. O Neoliberalismo: história e implicações. São Paulo: Ed. Loyola, 2008.

JARAMILLO GONZÁLEZ, Samuel. Hacia una teoria de la renta del suelo urbano. 2. ${ }^{a}$ ed. Bogotá: Universidad de los Andes, Facultad de Economía, CEDE, Ediciones Uniandes, 2009.

LEFEBVRE, Henri. A Cidade do Capital. Rio de Janeiro: DP\&A, 2001.

LEFEBVRE, Henri. Espaço e política. Belo Horizonte: Ed. UFMG, 2008. 
LÖWY, Michael. A teoria do desenvolvimento desigual e combinado. Actuel Marx, São Paulo, N. 18, p. 73-80, 1995. Tradução de Henrique Carneiro. Disponível em: http://www.revistaoutubro.com.br/versaofinal/ edicoes/01/out01_06.pdf

NASCIMENTO, Agnaldo; MOREIRA, Lucas A. e CASTRO, Paulo H. Vazios Urbanos - Londrina. Instituto de Pesquisa e Planejamento Urbano de Londrina (IPPUL) - Prefeitura Municipal de Londrina (PML), 2010.

NOGUEIRA, Paulo M. O capital imobiliário: acumulação, ciclo e crise. 2009. Dissertação de Mestrado (Mestrado em Geografia). Departamento de Geografia - Universidade Estadual do Ceará, Fortaleza, 2009.

RAZENTE, Nestor. A ocupação do espaço urbano de Londrina. 1984. Dissertação de Mestrado. (Mestrado em Desenvolvimento Urbano e Regional). Departamento de Arquitetura e Urbanismo - Mestrado em Desenvolvimento Urbano e Regional da Universidade Federal de Pernambuco, 1984.

RIBEIRO, Luiz C. de Q. Dos cortiços aos condomínios fechados. Rio de Janeiro: Civilização Brasileira, 1997.

SANTOS, Milton. A Totalidade do Diabo: Como as Formas Geográficas Difundem o Capital e Mudam as Estruturas Sociais. In: Economia Espacial. Críticas e Alternativas. São Paulo: Edusp, 2003.

O Estado-Nação como Espaço, Totalidade e Método. In: Da totalidade ao lugar. São Paulo: Edusp, 2008a.

SANTOS, Milton. Sociedade e Espaço: A Formação Social como Teoria e como Método. In: Da totalidade ao lugar. São Paulo: Edusp, 2008b.

SMITH, Neil. Desenvolvimento desigual. Natureza, Capital e a Produção de Espaço. São Paulo: Bertrand Brasil, 1984.

SMITH, Neil. Contornos de uma política espacializada: Veículos dos sem-teto e produção de escala geográfica. In: ARANTES, Antônio A. (org.). O Espaço da Diferença. Campinas: Papirus, 2000.

TOPALOV, Christian. Análise do ciclo de reprodução do capital investido na produção da indústria da construção civil. Capital e Propriedade Fundiária. In: FORTI, Reginaldo (org.). Marxismo e urbanismo capitalista. Textos críticos. São Paulo: Editora Ciências Humanas, 1979.

VALENÇA, Márcio M. Cidades ingovernáveis? Ensaio sobre o pensamento harveyano acerca da urbanização do capital. In: SILVA, José B. da; LIMA, Luiz C. e ELIAS, Denise (org). Panorama da Geografia brasileira. São Paulo: Annablume, 2006.

VALENÇA, Márcio M. Ensaio sobre a dinâmica do imobiliário em Harvey. In: (Org.). Cidade (i) legal. Rio de Janeiro: MAUAD, V. 1, 2008.

Trabalho enviado em abril de 2011 Trabalho aceito em julho de 2011 